\title{
Lip Epidermoid Cyst Caused by a Piercing: A Report of a Rare Case
}

\author{
Takashi Ito, Satoshi Fukuzawa $\left(\mathbb{D}\right.$, Kenji Yamagata $\left(\mathbb{D}\right.$, Shohei Takaoka ${ }^{(D)}$, \\ Makiko Ohkubo-Sato, Fumihiko Uchida, Naomi Ishibashi-Kanno, and Hiroki Bukawa
}

Department of Oral and Maxillofacial Surgery, Faculty of Medicine, University of Tsukuba, Tennodai 1-1-1, Tsukuba, Ibaraki 305-8575, Japan

Correspondence should be addressed to Satoshi Fukuzawa; sfukuzawa3104@yahoo.co.jp

Received 4 January 2022; Revised 23 January 2022; Accepted 26 January 2022; Published 8 February 2022

Academic Editor: Rui Amaral Mendes

Copyright (c) 2022 Takashi Ito et al. This is an open access article distributed under the Creative Commons Attribution License, which permits unrestricted use, distribution, and reproduction in any medium, provided the original work is properly cited.

\begin{abstract}
We report the case of a lip epidermoid cyst, caused by piercing in a 23-year-old Japanese woman. She had an exophytic lesion in the lower lip associated with the piercing which was initially diagnosed as a mucous retention cyst. The lesion was resected under local anesthesia, and pathological examination revealed an epidermoid cyst, likely caused by piercings. Piercing-induced epidermoid cysts frequently occur in the tragus. There have been no reports of piercing-induced epidermoid cysts developing in the oral cavity. To our knowledge, this is the first report of a lip epidermal cyst caused by piercings. Six months have passed since the operation, and it has not recurred.
\end{abstract}

\section{Introduction}

Body piercings have emerged as a component of recent fashion trends. They are worn on the ears and oral region, specifically the tongue and lips [1]. Epidermoid cysts are encountered in all parts of the body and occur $1.6 \%$ of times in the oral cavity [2]. There are also rare reports that it has become malignant [3]. However, to our knowledge, lip epidermal cysts caused by piercings have not been reported. We report the case of an epidermoid lip cyst caused by piercings.

\section{Case Report}

The patient was a 23-year-old Japanese woman with unremarkable medical and family histories. Five years prior, she had her lower lip pierced, such that it penetrated the left side of the lip and the skin. She stopped wearing her piercings after a few months, and the piercing holes closed spontaneously. Wound indurated or swelling was not noted.

When she was 22 years old, she had her left lower lip pierced again. The earrings were inserted twice. However, the pierced hole from the first set of piercings had been occluded. A mass appeared on the lower lip two months later, and the patient reported to our department due to its persistence.

Intraoral examination revealed a palpable mass, measuring approximately $4 \times 4 \mathrm{~mm}$, on the left lower lip. The piercing was in contact with the mass and penetrated the skin and mucosa of the lower-left lip (Figures 1 and 2).

She was clinically diagnosed with a mucous retention cyst of the lower lip. She was instructed to stop using her piercings two weeks before undergoing the lesion resection. 


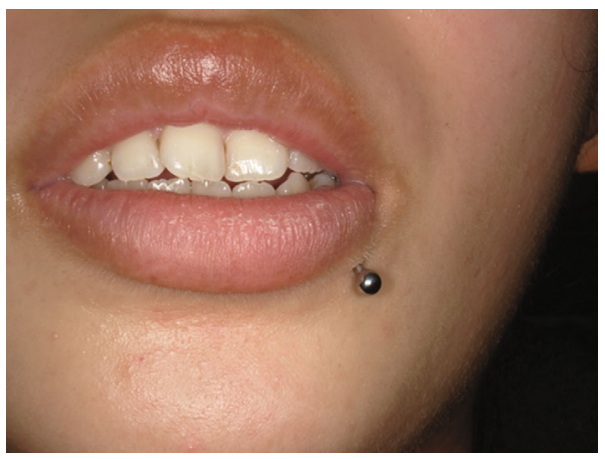

Figure 1: Extraoral findings.

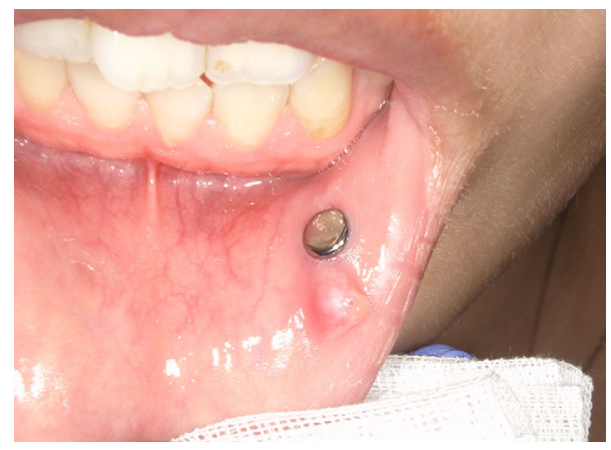

Figure 2: Intraoral finding. Tumor formation on the lip mucosa on the mesial side of the lip piercing.

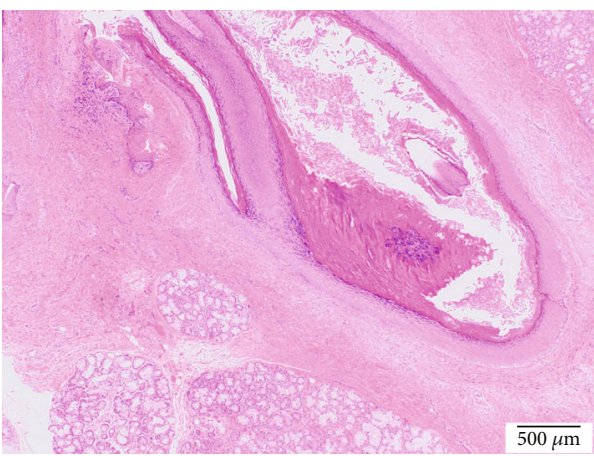

(a)

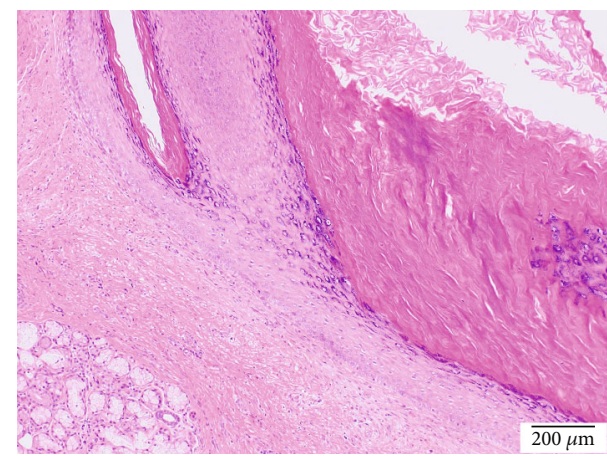

(b)

Figure 3: Histopathological findings of the lip cyst. (a) Hematoxylin and eosin stain $\times 4$. (b) Hematoxylin and eosin stain $\times 100$. A cyst covered with keratinized stratified squamous epithelium. Keratin is stored in the cyst.

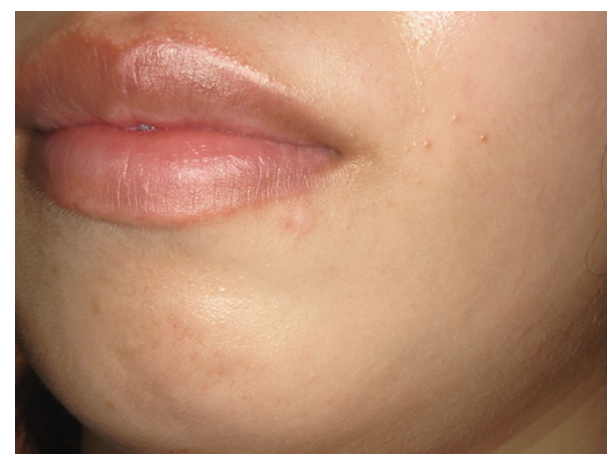

FIgURE 4: Extraoral finding 10 months after the surgery. 


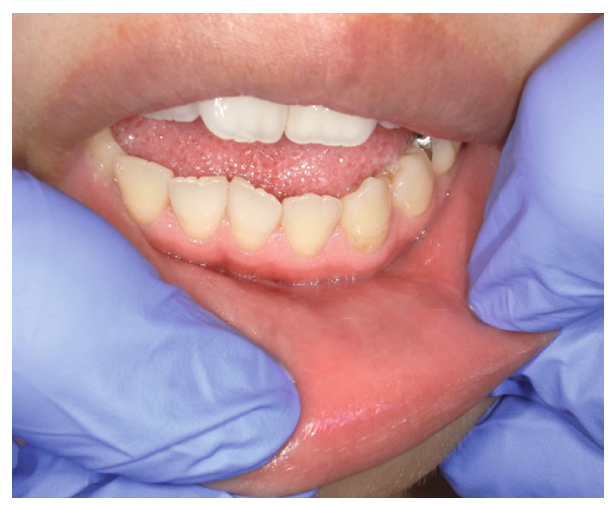

FIgURE 5: Intraoral finding 10 months after the surgery. The wound 10 months after surgery. No recurrence was noted.

The pierced hole was closed intraoperatively. The lesion and the scar on the pierced hole were resected under local anesthesia. Histopathological examination revealed a keratincontaining cyst covered with keratinized stratified squamous epithelium. Therefore, the patient was pathologically diagnosed with an epidermoid cyst (Figure 3).

One year has passed since the operation, and the wound has resolved without infection or recurrence (Figures 4 and 5).

\section{Discussion}

Piercings has been often applied to the tragus. Piercing complications in the tragus reportedly occur in 35\% [4]. Piercings have main complications including infections, allergic reactions, keloid formation, and traumatic lacerations.

Epidermal cysts are soft tissue cysts that commonly develop in the head and neck regions. Congenital causes are associated with invasion and residual embryonic ectoderm. These causes acquired epithelial tissue invasion, such as trauma and inflammation [5].

Kim et al. reported that 14 out of 132 people with tragus piercing complications have experienced epidermoid cysts [6]. Epidermoid cysts, caused by piercings, occur during infection or bleeding. Epidermoid cysts reportedly develop when patients stop using their piercings [7].

Epidermoid cysts are attributed to epithelial invasion and remnants at the ectodermic fusion in the congenital and to the implantation of keratinized epithelium by trauma in the acquired cases $[5,8]$. Epidermoid cysts on the lip due to trauma have also been reported due to denture irritation [9].

Chen et al. were the first to report the complications of oral piercings in 1992, and several cases have been reported after that [10]. The major complications of oral piercing are gingival recession and tooth fractures [11-13]. However, epidermoid cysts have not been reported, as complications associated with lip piercings. To the extent of our knowledge, this was the first case report on the occurrence of lip epidermoid cysts with such causality. In our case, the piercings were inserted twice. However, the pierced hole from the first set of piercings had occluded. The epidermoid cyst formation possibly occurred during that time. Alternatively, the epithelium might have invaded under the lip membrane after the second insertion, forming an epidermoid cyst.
According to the patient, the cyst developed two months after she had gotten her second set of piercing. However, she did not notice the cyst during the second insertion. Based on this, the second insertion likely caused epithelial invagination.

The process of receiving piercings is invasive, but the publicity materials on its complications have been few.

Since piercings have emerged as a component of the recent fashion trends, cases like the present case may become more common in the future. Thus, dentists and oral surgeons should consider this a differential diagnosis. Moreover, people should be informed regarding the potential complications and risks associated with oral piercings.

\section{Data Availability}

The data used to support the findings of this study are included within the article.

\section{Ethical Approval}

This article does not contain any studies with animals performed by any of the authors.

\section{Consent}

Informed consent has been obtained from the patient for this publication.

\section{Conflicts of Interest}

The authors declare that they have no conflict of interest.

\section{References}

[1] R. J. G. Moor, A. M. J. C. De Witte, K. I. M. Delmé, M. A. A. De Bruyne, G. M. G. Hommez, and D. Goyvaerts, "Dental and oral complications of lip and tongue piercings," British Dental Journal, vol. 199, no. 8, pp. 506-509, 2005.

[2] S. Mahalakshmi, S. Reddy, T. K. Ramamurthy, and B. Shilpa, "Rare locations of epidermoid cyst: case reports and review," Ethiopian Journal of Health Sciences, vol. 26, no. 6, pp. 595601, 2016.

[3] V. Bhatt, M. Evans, and T. J. Malins, "Squamous cell carcinoma arising in the lining of an epidermoid cyst within the 
sublingual gland - a case report," The British Journal of Oral \& Maxillofacial Surgery, vol. 46, no. 8, pp. 683-685, 2008.

[4] T. C. Simplot and H. T. Hoffman, "Comparison between cartilage and soft tissue ear piercing complications," American Journal of Otolaryngology, vol. 19, no. 5, pp. 305-310, 1998.

[5] R. L. Ettinger and R. D. Manderson, "Implantation keratinizing epidermoid cysts: A review and case history," Oral Surgery, vol. 36, no. 2, pp. 225-230, 1973.

[6] M. S. Kim, I. G. Song, K. C. Choi, and B. S. Shin, "Study of complications of ear piercing," Korean Journal of Dermatology, vol. 49, no. 1, pp. 20-27, 2011.

[7] M. Kurokawa and Y. Ishii, "Treatment for epidermal cyst following ear piercing," J JSAPS, vol. 21, no. 2, pp. 101-105, 1999.

[8] F. S. De Ponte, A. Brunelli, E. Marchetti, and D. J. Bottini, "Sublingual epidermoid cyst," The Journal of Craniofacial Surgery, vol. 13, pp. 308-310, 2002.

[9] J. C. Kim and I. P. Hong, "Rare Giant upper lip epidermal cyst in a patient wearing a denture," Archives of Craniofacial Surgery, vol. 17, no. 4, pp. 222-224, 2016.

[10] M. Chen and C. Scully, "Tongue piercing: a new fad in body art," British Dental Journal, vol. 172, no. 3, pp. 87-895, 1992.

[11] E. W. King, E. Brewer, and P. Brown, "Oral piercings and their complications - how confident are we as a profession?," British Dental Journal, vol. 224, no. 11, pp. 887-895, 2018.

[12] P. López Jornet, C. Navarro-Guardiola, F. Camacho-Alonso, V. Vicente-Ortega, and J. Yánez-Gascon, "Oral and facial piercings: a case series and review of the literature," International Journal of Dermatology, vol. 45, no. 7, pp. 805-809, 2006.

[13] A. Plessas and E. Pepelassi, "Dental and periodontal complications of lip and tongue piercing: prevalence and influencing factors," Australian Dental Journal, vol. 57, no. 1, pp. 71-78, 2012. 